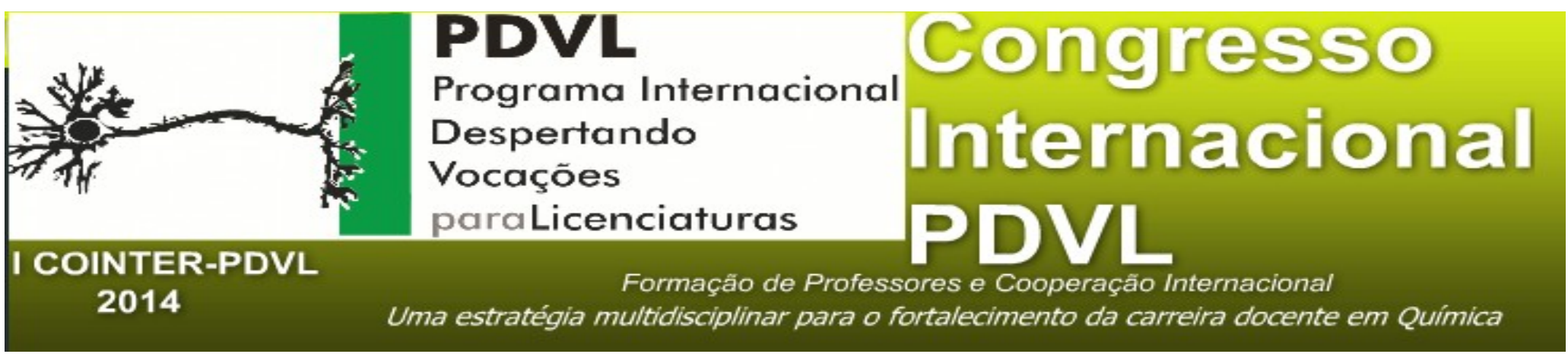

\title{
APLICAÇÃO DE JOGOS DIDÁTICOS PARA FACILITAR A APRENDIZAGEM DA QUÍMICA NO ENSINO FUNDAMENTAL
}

\begin{abstract}
Apresentação: Pôster
Bárbara Elizabeth Alves de Magalhães ${ }^{1}$; Alexandre Gomes Marques de Freitas²; Tiago Santos Silva ${ }^{3}$
\end{abstract}

\section{Introdução}

Geralmente, os alunos são apresentados à Química no nono ano do Ensino Fundamental, na disciplina de Ciências. Nesse contexto, a metodologia empregada pode instigar os alunos ou criar uma barreira ente o aluno e a disciplina, que será aprofundada ao longo do Ensino Médio. A metodologia tradicional, em geral, desenvolve nos alunos resistência em relação à disciplina, por isso é necessário que o professor busque não se ater ao método tradicional e realize aulas diferenciadas, mais dinâmicas (SAIDELLES et al., 2012). As possibilidades para melhorar o processo de ensino-aprendizagem da disciplina de Química são muitas, como buscar a interdisciplinaridade, a contextualização, a experimentação e a ludicidade.

Considerando os aspectos expostos, o estudo apresentado objetivou buscar a melhoria no processo de ensino-aprendizagem de Química na disciplina de Ciências, através de uma metodologia capaz de tornar o ensino da disciplina mais descontraído e a aprendizagem mais

1 Licenciatura Plena em Química/IF Sertão Pernambucano Campus Ouricuri/barbara.elisabeth@hotmail.com

2 Licenciatura Plena em Química/IF Sertão Pernambucano Campus Ouricuri/alexandremarquesbdc@yahoo.com.br

3 Médico Veterinário/IF Sertão Pernambucano Campus Ouricuri/tiagoifsertao@gmail.com 
significativa. O presente estudo foi realizado durante a execução do Estágio Supervisionado I, no período de março a maio de 2014, em duas turmas de $9^{\circ}$ ano do ensino fundamental da Escola Estadual Dom Idílio José Soares em Ouricuri-PE.

Durante o período de observação do estágio, foi percebido que muitos alunos passavam seu tempo livre na biblioteca, com jogos disponibilizados pela escola, como damas, jogos da memória e quebra-cabeças. Também foi observado que os alunos não apresentavam um bom entendimento dos assuntos e não tinham interesse pelas aulas de Ciências, que eram apenas voltadas para a metodologia tradicional, priorizando a memorização e reprodução dos conceitos do livro didático.

Para a etapa de regência do estágio foram adotadas diferentes estratégias de ensino, buscando realizar aulas diferenciadas, capazes de integrar os interesses dos alunos e de facilitar o desenvolvimento dos conhecimentos específicos da Química. Objetivou-se proporcionar ao aluno uma aprendizagem significativa, permitindo que ele estabeleça uma relação entre o conteúdo estudado e sua realidade, seja capaz de elaborar conceitos e de perceber a Química como algo útil e presente em sua vida.

Os alunos, geralmente, têm a crença de que a tabela periódica é algo extremamente complexo e muito difícil de compreender. Para desmistificar essa ideia, foi abordado o conteúdo de tabela periódica através de aulas expositivas com auxílio de recursos multimídia, da proposição de pesquisa e socialização sobre os elementos incluídos mais recentemente na tabela periódica, e da aplicação de dois jogos didáticos. A avaliação do conteúdo foi feita de forma gradual, mediante a participação dos alunos durante as aulas e nas atividades propostas.

\section{Fundamentação Teórica}

Castro e Costa (2011) propõem que as atividades lúdicas em sala de aula constituem uma metodologia alternativa que pode auxiliar na apropriação dos conteúdos e gerar uma aprendizagem significativa. Para Cunha (2012), os jogos no ensino são atividades diferenciadas que possuem regras e são controladas pelo professor, mas que não perdem as características de ludicidade e liberdade. A depender das características e do planejamento do professor, os jogos podem ser usados como recurso didático de diferentes formas, no entanto, não devem ser usados apenas para tornar a aula mais descontraída.

Os jogos didáticos permitem que os alunos participem mais das aulas, por isso auxilia no 
processo de ensino-aprendizagem de Química. Inserindo atividades prazerosas nas aulas, os jogos instigam os alunos, proporcionando a construção e o aperfeiçoamento da aprendizagem dos conteúdos (SAIDELLES et al., 2012). A prioridade dos jogos didáticos deve ser permitir ao aluno se divertir e ter liberdade para elaborar conceitos por si mesmo. É muito importante que os jogos didáticos ofereçam a oportunidade de construção do conhecimento para todos, de modo que as particularidades dos alunos sejam consideradas.

\section{Metodologia}

A pesquisa realizada, voltada para o ensino de Química nas aulas de Ciências, foi realizada com 78 alunos de duas turmas do nono ano do Ensino Fundamental da Escola Estadual Dom Idílio José Soares em Ouricuri-PE, propôs apresentar o conteúdo de tabela periódica em uma aula diferenciada e, combinando metodologias quantitativa e qualitativa, avaliar a aprendizagem dos alunos a cerca do conteúdo.

Em aulas expositivas e dialogadas foram apresentados o histórico da organização da tabela periódica, os conceitos de grupo e período, a origem e os nomes dos elementos, a classificação dos elementos como metais e ametais, os estados físicos dos elementos em condições ambientes e foram revisados os conceitos de número atômico e massa atômica. Os elementos fleróvio e livermório ainda não estão incluídos na tabela periódica contida no livro didático dos alunos, por isso foi proposto aos alunos a pesquisa sobre esses elementos, quanto à descoberta, o reconhecimento e as características desses elementos. Na aula seguinte, os alunos foram instigados a falar sobre o que descobriram em suas pesquisas, apontando o que considerou mais interessante.

Para facilitar a assimilação dos símbolos e nomes dos elementos da tabela periódica e fixar os conceitos apresentados nas aulas, além de possibilitar o conhecimento das principais aplicações de alguns elementos químicos, foram elaborados e aplicados dois jogos didáticos. Para integrar todos os alunos, cada turma foi dividida em dois grupos, que ao finalizar a partida de um jogo, trocou de jogo com o outro grupo. No jogo apresentado na figura 1, foi proposto aos alunos relacionar os símbolos e os nomes dos elementos representativos, organizando-os em seus respectivos grupos. Alguns símbolos foram colocados com a imagem de uma aplicação, para instigar os alunos a perguntar sobre a aplicação do elemento ou de um composto do qual é componente. Cada aluno deveria relacionar ao menos dois símbolos aos seus respectivos nomes e os componentes do grupo poderiam, e deveriam, auxiliar uns aos outros. 


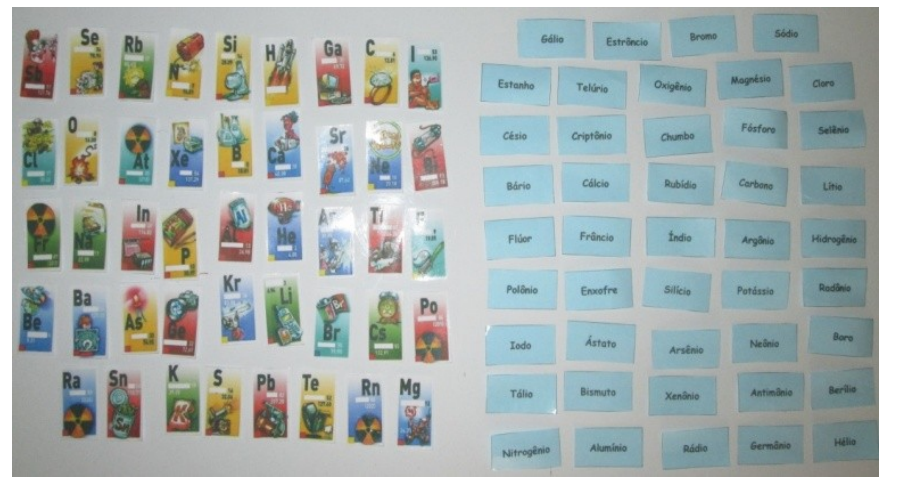

Figura 1: jogo para relacionar o símbolo ao nome do elemento

No jogo apresentado na figura 2, foi proposto ao aluno identificar o símbolo e o nome do elemento em uma tabela não preenchida a partir de cartões com imagens da aplicação do elemento ou de um de seus compostos na frente e dicas sobre o grupo e o período do elemento no verso. Cada aluno deveria identificar dois elementos na tabela, podendo auxiliar e ser auxiliado pelos colegas.

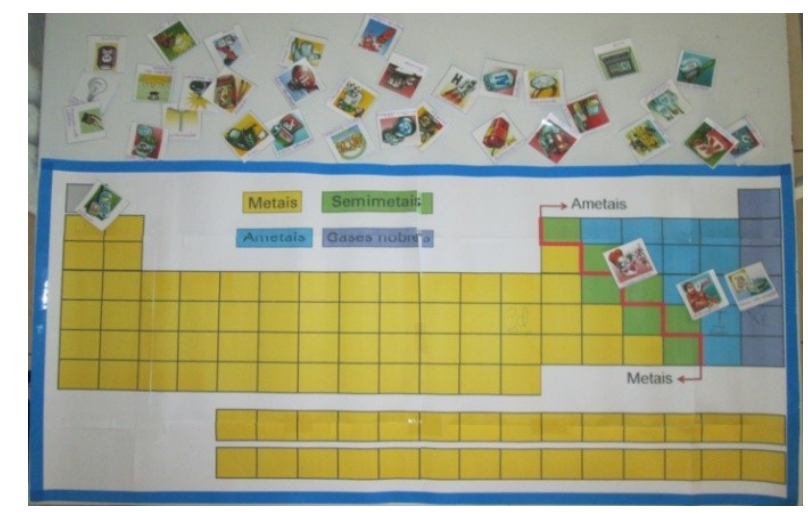

Figura 2: jogo para identificar o elemento na tabela

Por fim, após a aplicação dos jogos, foi aplicado um questionário simples com cinco questões para conhecer as opiniões dos alunos e avaliar a aceitação deles em relação a aula.

\section{Resultados e Discussões}

Os jogos didáticos são um instrumento didático que possibilita que o aprendizado ocorra de forma simples e prazerosa, e que atua como um elemento motivador para os alunos no estudo da Química (CASTRO e COSTA, 2012). O aprendizado dos alunos melhorou com a aplicação dos jogos, o que foi refletido nas notas. No estudo comparativo das notas, foi constatado que a minoria (46\%) dos alunos havia conseguido alcançar a nota média $(7,0)$ nas atividades realizadas baseadas na metodologia tradicional, percentual que aumentou para 81\% depois dos jogos. 
Durante a observação da execução dos jogos didáticos, foi percebido o interesse dos alunos em participar da atividade. No questionário aplicado depois dos jogos, foi identificado que $61 \%$ dos alunos não consegue aprender com aulas apenas teóricas, 67\% nunca havia usado jogos na aula para estudar o conteúdo trabalhado, para 91\% foi mais fácil aprender o conteúdo com os jogos e 97\% gostariam de ter mais aulas diferenciadas, como mostra o gráfico a seguir.

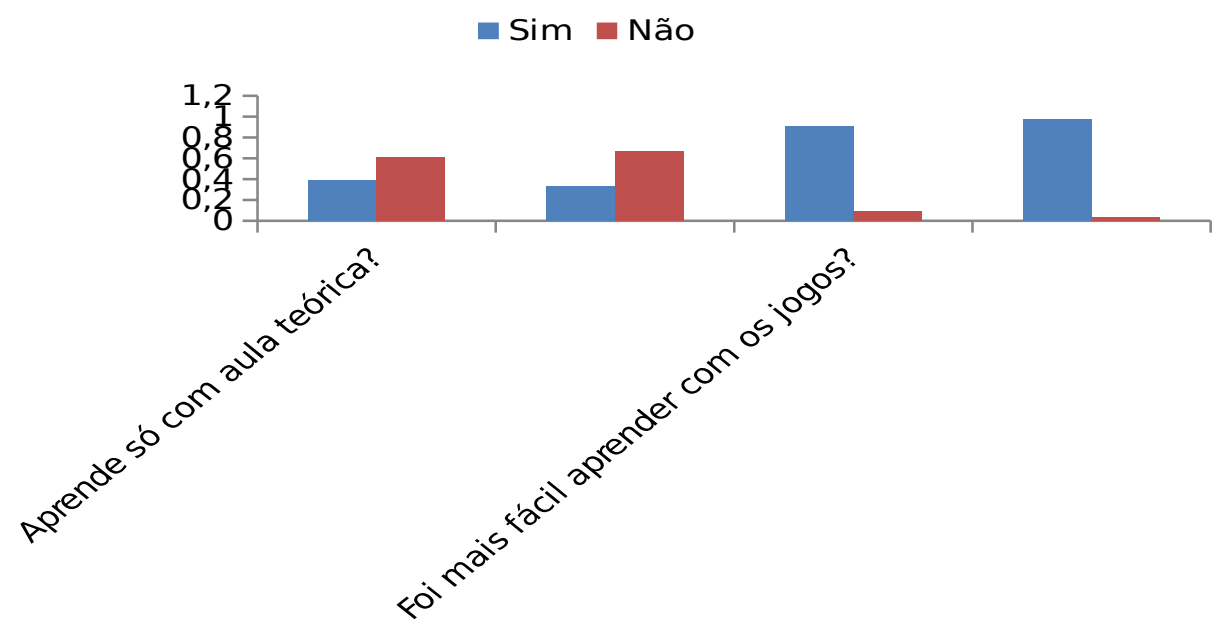

Gráfico 1: respostas dos alunos no questionário

\section{Conclusões}

A aplicação de jogos didáticos permite que o aluno construa sua aprendizagem de forma significativa e se divertindo. A partir dos resultados obtidos e da observação da execução dos jogos, conclui-se que a metodologia aplicada neste projeto contribuiu para o desenvolvimento do processo de ensino aprendizagem do conteúdo tabela periódica na disciplina de Ciências no nono ano do ensino fundamental. O conteúdo em questão é abordado de forma mais aprofundada no primeiro ano do Ensino Médio na disciplina de Química, por tanto é sugerido que a metodologia apresentada também possa ser aplicada nessa situação para relembrar e fixar conceitos.

\section{Referências}

CASTRO, Bruna Jamila de; COSTA, Priscila Caroza Frasson. Contribuições de um jogo didático para o processo de ensino e aprendizagem de Química no Ensino Fundamental segundo o contexto da Aprendizagem Significativa. Revista electrónica de investigación en educación en ciências. v. 6, n. 2, p. 1-13, 2011. 
CUNHA, Marcia Borin da. Jogos no ensino de química: considerações teóricas para sua utilização em sala de aula. Química nova na escola. v. 34, n. 2, p. 92-98, 2012.

SAIDELLES, Ana Paula Fleig; CRUZ, Litiele Cezar da; KIRCHNER, Rosane Maria; PIVOTTO, Otávio Lavarda; SANTOS, Douglas Silva dos; SANTOS, Nara Rejane Zamberlan dos. Jogo didático como auxiliar para o aprendizado em química. 2012. 